\title{
Sulfur Geochemistry of Mining Impacted Waters
}

\author{
S. MARSHALL ${ }^{1}$, T. COLENBRANDER-NELSON ${ }^{2}$, D. \\ BENNETT $^{1}$, S.C. APTE ${ }^{3}$, AND L.A. WARREN ${ }^{2 *}$ \\ ${ }^{1}$ McMaster University, Hamilton, Canada \\ (marshs1@mcmaster.ca) \\ ${ }^{2}$ University of Toronto, Toronto, Canada \\ (correspondence: lesley.warren@utoronto.ca; \\ tara.nelson@utoronto.ca) \\ ${ }^{3}$ CSIRO Land and Water, NSW, Austrailia; \\ simon.apte@csiro.au
}

The presence of sulfur oxidation intermediates (SOIs, commonly referred to as thiosalts) in mining wastewater is a significant industry-wide concern because of the potential for acidification and toxicity of receiving water bodies. The goal of this project was to establish a robust geochemical baseline of mining waters from which adapative management strategies can be developed. Samples were collected within a wastewater treatment system of a northern Ontario base metal mining operation across 12 seasonal and annual campaigns from 2014 to 2016 . The objectives were to determine the water balance for the system, including the tailings basin (Ox Res) and its inputs, as well as to characterize the physicochemical profiles and associated sulfur mass balance of the Ox Res water cap ( $\sim 35 \mathrm{~m})$.

The volume of the Ox Res was $\sim 20 \mathrm{Mm}^{3}$ with an epilimnetic residence time (where all inputs report) of $\sim 1.5$ months. The largest input contribution was natural watershed inputs $(56 \%)$ followed by mine water $(22 \%)$ and tailings (18\%). However, the combined mine water and tailings inputs contribution increased to $76 \%$ (2015) and $100 \%$ (2016) during the summer stratification period. A recorded epilimnetic depth of $2 \mathrm{~m}$ in 2015 and 1.5 in 2016, represent the shallowest summer thermoclines (and epilimnetic volumes) on record since 1994.

Changes in water balance were reflected in Ox Res epilimnetic water chemistry. The epilimnetic summer $\mathrm{pH}$ of the typically circumneutral Ox Res became acidic (4.6) in 2016. Sulfur mass balance identified that 2016 also had a far lower maximum proportion $(0-7 \%)$ of sulfur oxidation intermediates (SOI), consistent with greater microbial $\mathrm{S}$ oxidation processes occurring, relative to $2015(0-75 \%)$. The presence of SOIs can present water quality risks for receiving environments as they can be challenging to manage and treat with a $100 \%$ efficiency. The interactive hydrological, operational and biogeochemical mechanisms contributing to these observed patterns in sulfur geochemistry will be presented. 